\title{
Leptospirosis in a child with acute respiratory distress syndrome
}

\author{
Osman Yeşilbaş ${ }^{1}$, Esra Şevketoğlu ${ }^{1}$, Hasan Serdar Kıhtır ${ }^{1}$, Nevin Hatipoğlu ${ }^{2}$, \\ Hamdi Murat Yıldırım¹, Mehmet Bedir Akyol ${ }^{3}$, Nuray Aktay-Ayaz ${ }^{4}$, İbrahim Gökçe ${ }^{5}$ \\ Departments of ${ }^{1}$ Pediatric Intensive Care Unit, ${ }^{2}$ Pediatric Infectious Disease, ${ }^{3}$ Pediatric Cardiology, Bakirkoy Dr. Sadi \\ Konuk Research and Training Hospital, ${ }^{4}$ Department of Pediatric Rheumatology, Kanuni Sultan Süleyman Research and \\ Training Hospital, ${ }^{5}$ Department of Pediatric Nephrology, Marmara University Medical Faculty Hospital, Istanbul, Turkey. \\ E-mail: drosmanyesilbas@gmail.com
}

Received: 25th November 2016, Revised: 6th March 2017, Accepted: 6th March 2017

SUMMARY: Yeşilbaş O, Şevketoğlu E, Kıhtır HS, Hatipoğlu N, Yıldırım HM, Akyol MB, Aktay-Ayaz N, Gökçe I. Leptospirosis in a child with acute respiratory distress syndrome. Turk J Pediatr 2017; 59: 688-692.

Leptospirosis is an infectious vasculitis, which can occur with different clinical features. While it is generally a subclinical and self-limited infection; kidney and liver dysfunction, pulmonary hemorrhage, thrombocytopenia, and cardiovascular collapse may occurr. A six-year-old boy presented with acute respiratory distress syndrome, shock, thrombocytopenia-associated multiple organ failure, and persistent high fever secondary to leptospirosis. Persistent high fever was resistant to intravenous immunoglobulin and pulse steroid therapy. He was successfully treated with plasmapheresis and hemofiltration with endotoxin-cytokine cleaning filter. In conclusion; leptospirosis may cause thrombocytopenia-associated multiple organ failure, persistent high fever, and acute respiratory distress syndrome. Plasmapheresis and hemofiltration should be considered in cases of severe leptospirosis with multiorgan failure.

Key words: acute respiratory distress syndrome, leptospirosis, persistent high fever, thrombocytopenia-associated multiple organ failure.

Leptospirosis is an infectious disease with different clinical manifestations characterized by the development of vasculitis. The disease mostly presents with nonspecific symptoms such as fever, myalgia, headache, and conjunctivitis. While it is generally a subclinical and self-limited infection, $5-10 \%$ of the disease manifests as kidney and liver dysfunction, pulmonary hemorrhage, thrombocytopenia, and cardiovascular collapse. ${ }^{1,2}$

This report describes a six-year-old boy that was presented with acute respiratory distress syndrome (ARDS), shock, thrombocytopeniaassociated multiple organ failure (TAMOF), and persistent high fever during hospitalization in the pediatric intensive care unit (PICU).

\section{Case Report}

A six-year-old boy was referred to our PICU with fever for two days, vomiting, diarrhea, hypotension, and respiratory distress. On admission he was lethargic and febrile $\left(39^{\circ} \mathrm{C}\right)$. His pupils were miotic and reactive to light. $\mathrm{He}$ had subcostal and intercostal retractions and tachypnea. Breath sounds were equal with wide crackles and he was intubated soon after admission. He was tachycardic, hypotensive and capillary refill time was six seconds. $\mathrm{He}$ had macular erythema with desquamation in the groin and genital areas.

Laboratory findings showed metabolic acidosis with normal lactate level. Complete blood count with differential revealed a white blood cell level of $10100 / \mathrm{mm}^{3}$, hemoglobin level of $9.1 \mathrm{~g} / \mathrm{dL}$, hematocrit level of $28.6 \%$ and platelet level of $208000 / \mathrm{mm}^{3}$. Prothrombin time was 20.5 seconds and activated partial thromboplastin time was 41.6 seconds. The renal function tests were deranged with a 
blood urea of $82 \mathrm{mg} / \mathrm{dl}$ and serum creatinine of $2.8 \mathrm{mg} / \mathrm{dl}$. He had mildly elevated liver enzymes and hypoalbuminemia (Table I). There was widespread infiltration on the first chest radiograph with a rapid progression to ARDS (Fig 1).

Toxic shock syndrome was considered because of fever up to $39 \mathrm{C}$, peelings of the skin at the groin and genital area. Clindamycine, vancomycin and clarithromycin were added to current ceftriaxone treatment and adrenaline infusion was started. Left subclavian dialysis catheter (9 french) was inserted and continuous venovenous hemofiltration (CVVHF) was started with endotoxin-cytokine cleaning filter (Prismaflex,Oxiris ${ }^{\circledR}$, Gambro Lundia $A B$, Sweden) for treatment of the toxic shock syndrome and oliguria. Replacement fluid rate was performed as $70 \mathrm{ml} / \mathrm{kg}$. On the second day of admission, platelet count decreased to $77,000 / \mathrm{mm}^{3}$. Thrombocytopenia-associated multiple organ failure was diagnosed and daily plasmapheresis with fresh frozen plasma (FFP) was started and continued for 4 days. Plasmapheresis was obtained by plasma filtration (Prismaflex, TPE1000 filter, Gambro Lundia AB, Sweden). Plasma exchange volume was calculated as follows; $0.065 \times \mathrm{kg} \times(1-\mathrm{Htc})$.

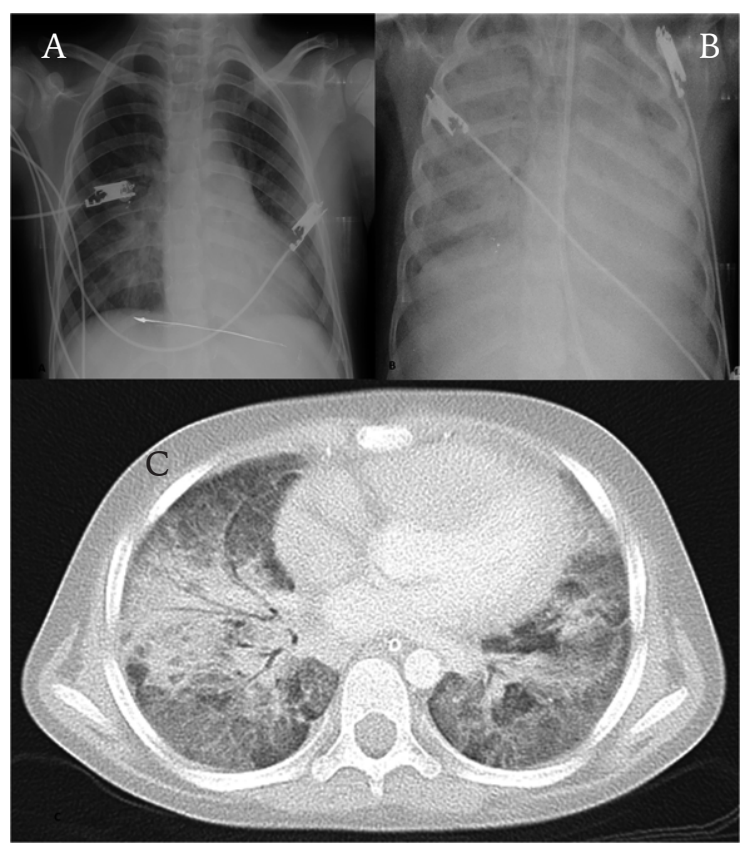

Fig. 1. A: Patient's chest X-ray on the first day of admission. B: Patient's chest X-ray on the second day of admission. C: Patient's thorax computerized tomography.
Plasmapheresis was performed over 3-4 hours. During CVVHF and plasmapheresis, heparin was used for anticoagulation and titrated to maintain the activated clotting time between 180 and 220 seconds. Also in two treatment procedures, blood flow rate was performed as $100 \mathrm{ml} / \mathrm{min}(5 \mathrm{ml} / \mathrm{kg})$. On the fourth day, Intravenous immunoglobulin $(1 \mathrm{~g} / \mathrm{kg})$ was started for severe sepsis and mild IgG deficiency $(255 \mathrm{IU} / \mathrm{ml}$, normal range for age: 633-1280 IU/ml).

Repeated blood, tracheal aspirate and urine cultures were sterile. Serological tests for viruses and bacteria (influenza, parainfluenza, respiratory syncytial virus, adenovirus, Mycoplasma and Chlamydia pneumonia, Crimean-Congo hemorrhagic fever, measles, rubella, mumps, Ebstein-Barr virus, cytomegalovirus, human immunodeficiency virus, herpes simplex virus, parvovirus B19, brucella and salmonella) were negative. In cerebrospinal fluid (CSF) examination; the protein level was $42 \mathrm{mg} / \mathrm{dl}$, glucose level was $101 \mathrm{mg} / \mathrm{dl}$ (simultaneous serum glucose level was $132 \mathrm{mg} / \mathrm{dl}$ ). Mild CSF-pleocytosis [WBC $20 / \mathrm{mm}^{3}$ (lymphocyte 100\%)] were observed in direct microscopic examination. Cerebrospinal fluid culture was concluded as sterile.Tuberculin skin test was performed and resulted as four milimeters. Quantiferon and galactomannan were negative. Echocardiography was normal.

On the fifth day, he had developed supraventricular tachycardia episodes. Leptospirosis was considered because of persistent fever, thrombocytopenia, renal failure, ARDS and supraventricular tachycardia. Spirochetes were demonstrated with dark field microscopy. Leptospira IgM and IgG were positive and leptospirosis was diagnosed.

On the thirteenth day, he still had a fever and daily plasmapheresis with FFP and CVVHF with endotoxin-cytokine cleaning filter (Oxiris ${ }^{\circledR}$, Gambro Lundia AB, Sweden) were started for removal of inflammatory cytokines. The fever could only be decreased during treatment with Oxiris ${ }^{\circledR}$ (Gambro Lundia AB, Sweden) filter hemofiltration.

Direct examination of bone marrow aspiration was normal and culture was negative. Laboratory tests (anti-nuclear antibody, antidsDNA, extractable nuclear antigen antibodies panel, lupus anticoagulant antiphospholipid, 
Table I. Laboratory Values during the First 10 Hospital Days.

\begin{tabular}{|c|c|c|c|c|c|c|c|c|c|c|}
\hline & 1 & 2 & 3 & 4 & 5 & 6 & 7 & 8 & 9 & 10 \\
\hline $\begin{array}{l}\text { White cells }\left(10^{3} /\right. \\
\left.\mathrm{mm}^{3}\right)\end{array}$ & 10100 & 24800 & 25200 & 18000 & 16700 & 16200 & 20400 & 27.600 & 28400 & 20600 \\
\hline ANC $\left(10^{3} / \mathrm{mm}^{3}\right)$ & 9250 & 21000 & 18600 & 11900 & 9000 & 9820 & 10600 & 16000 & 15900 & 12400 \\
\hline ANC (\%) & $\% 91.7$ & $\% 85.2$ & $\% 73.7$ & $\% 66.1$ & $\% 54$ & 60.8 & $\% 52.1$ & $\% 57.8$ & $\% 56.2$ & $\% 60.1$ \\
\hline Hemoglobin (g/dl) & 9.1 & 8 & 9.1 & 8.7 & 10.2 & 10 & 10.1 & 8.7 & 9 & 8 \\
\hline Hematocrit (\%) & 28.6 & 24.8 & 27.5 & 26.7 & 29.9 & 29.3 & 30.4 & 27.2 & 28 & 23.8 \\
\hline $\begin{array}{l}\text { Platelets }\left(10^{3} /\right. \\
\left.\mathrm{mm}^{3}\right)\end{array}$ & 208000 & 77000 & 56000 & 14000 & 24000 & 56000 & 144000 & 39000 & 25000 & 84000 \\
\hline PT (s) & 20.5 & 20.7 & 16.3 & 15.1 & 12.6 & 12.2 & 12 & 13.5 & 13.5 & \\
\hline INR & 1.9 & 1.9 & 1.5 & 1.3 & 1.1 & 1.1 & 1.0 & 1.2 & 1.2 & \\
\hline aPTT (s) & 41.6 & 40.2 & 62.5 & 63.1 & 44.7 & 78.6 & 31.8 & 43.1 & 37 & \\
\hline CRP (mg/dl) & 19.2 & 18.9 & 24.2 & 24.5 & 15.4 & 10.2 & 5.1 & 1.7 & 2.3 & 6.1 \\
\hline Creatinine $(\mathrm{mg} / \mathrm{dl})$ & 2.82 & 2.55 & 1.05 & 1.04 & 0.65 & 0.51 & 0.49 & 0.76 & 0.73 & 1.09 \\
\hline AST (U/L) & 102 & 102 & 66 & 68 & 59 & 46 & 40 & 352 & 306 & 98 \\
\hline ALT $(\mathrm{U} / \mathrm{L})$ & 47 & 53 & 40 & 43 & 43 & 36 & 37 & 140 & 214 & 119 \\
\hline $\begin{array}{l}\text { Total bilirubin } \\
(\mathrm{mg} / \mathrm{dl})\end{array}$ & 0.16 & 0.63 & 0.67 & & 0.59 & 0.74 & 0.64 & 0.66 & & 0.51 \\
\hline $\begin{array}{l}\text { Direct bilirubin } \\
(\mathrm{mg} / \mathrm{dl})\end{array}$ & 0.04 & 0.24 & 0.25 & & 0.18 & 0.21 & 0.15 & 0.18 & & 0.1 \\
\hline GGT (U/L) & 16 & 28 & 20 & 39 & 52 & 50 & 64 & 251 & 276 & 172 \\
\hline $\begin{array}{l}\text { Triglyceride (mg/ } \\
\text { dl) }\end{array}$ & 143 & 76 & 88 & 86 & & & 186 & 194 & 295 & 217 \\
\hline Albumin (g/dl) & 2.4 & 3.18 & 2.67 & 2.94 & 3.83 & 3.39 & 3.83 & 3.31 & 3.18 & 2.84 \\
\hline
\end{tabular}

ALT: alanine aminotransferase, AST: aspartate aminotransferase, ANC: absolute neutrophil count, aPTT: activated prothrombin time, CRP: C-reactive protein, GGT: gamma-glutamyl transpeptidase, PT: prothrombin time.

anticardiolipin, and anti-glomerular basement membrane antibody) for rheumatic diseases were negative.

On the twenty-fifth day in the PICU, fever persisted (except during hemofiltration with Oxiris ${ }^{\circledR}$ ) and desquamation were seen on the tips of the fingers and toes with widespread maculopapular rash, erythema of the oral mucosa, and non-purulent conjunctivitis. A rash appeared on his groin area with central pallor and peripheral erythema. Intravenous immunoglobulin $(2 \mathrm{~g} / \mathrm{kg})$ was started but the temperature was persistently high during two days of the treatment. On the twenty-eighth day, steroid pulse therapy $(30 \mathrm{mg} / \mathrm{kg}$ ) was started for three days but the fever persisted. On the fortieth day, the forcefulness of the fever declined and clinical findings began to improve. On the fifty-second day of hospitalization in the PICU, he was transferred to a pediatric room with a tracheostomy tube. At a three-year follow up after being discharged from the hospital the patient is completely healthy without a tracheostomy. Written informed consent was obtained from the patient's parent. 


\section{Discussion}

Leptospirosis is an infectious vasculitis, which can occur with different clinical features. Spirochetes live in renal tubular cells of wild and domestic animals. With the urine of these animals, the pathogen infects water and soil. The transmission to humans occurs via mucosa and broken skin exposure to contaminated water, soil or direct contact with the tissues of infected animals. ${ }^{1,2}$ Our patient had a history of exposure to turtles in an aquarium at his school.

The involvement of the pulmonary in leptospirosis occurs in $20 \%$ to $70 \%$ of patients, and clinical symptoms ranges from cough, breathlessness, chest pain, hemoptysis, and ARDS. ${ }^{3,4}$ Acute respiratory distress syndrome which is often associated with pulmonary hemorrhage is a rare manifestation of leptospirosis and has a high morbidity and mortality rate ${ }^{3}$. The suggested causal factors in the pathogenesis for lung involvement and ARDS are toxin and cytokine mediated endothelial damage and vasculitis which primarily affects capillaries. Myocarditis, renal failure, and hypervolemia secondary to leptospirosis are other possible contributing factors ${ }^{3}$. Our patient presented with ARDS without pulmonary hemorrhage and hypervolemia. He was successfully treated with lung protective ventilatory strategy (low tidal volume and high levels of positive end-expiratory pressure).

The main hypothesis about the vasculitis in leptospirosis is an immune response and cytokine storm which may be triggered by a superantigen in genetically susceptible children. Superantigens are virulent proteins that are excreted by a diversity of microorganisms. Numerous studies have shown that superantigens are a cause or at least a provocating agent to increase V-beta $2+\mathrm{T}$ cells in the leptospirosis. The $\mathrm{T}$ cells activation is related to the high levels of interleukin (IL)$1 \beta$ and tumor necrosis factor (TNF)- $\alpha$. These proinflammatory cytokines are the cornerstone in the pathophysiology of systemic vasculitis in this disease. ${ }^{5,6}$ Thrombocytopenia-associated multiple organ failure is an independent risk factor for poor outcome in critical illness. Plasmapheresis has been successfully used as a treatment for TAMOF. ${ }^{7}$ Our patient was diagnosed TAMOF due to leptospirosis and succesfully treated with plasmapheresis. The aim of plasmapheresis and CVVHF in leptospirosis is removal of endotoxins and inflammatory mediators as in sepsis. ${ }^{8} \mathrm{We}$ interestingly observed that the fever decreased dramatically when we used endotoxin-cytokine cleaning filter (Oxiris ${ }^{\circledR}$, Gambro Lundia AB, Sweden) for hemofiltration, whereas, the fever was persisted when we used standard hemofilter (HF1000, Gambro Lundia AB, Sweden). In recent years endotoxin cytokinecleaning filters (Oxiris ${ }^{\circledR}$, Gambro Lundia $A B$, Sweden) have been successfully used to capture increasing endotoxins and cytokines due to sepsis and systemic inflammation response syndrome. ${ }^{9,10}$ Persistent fever, erythema of the oral mucosa, non-purulent conjunctivitis, peelings and widespread maculopapular rash were considered as findings of Kawasaki disease coexist with leptospirosis. But these findings occurred very late in comparison with the typical course of Kawasaki disease. Additionally there was no abnormality of the coronary arteries and cervical lymphadenopathy despite 25 days of persistent high fever. It was thought that IVIG and pulse steroid could be effective for possible atypical Kawasaki disease and stopping the cytokine storm which was secondary to leptospirosis. Numerous adult case series and small studies have been published in the current literature about immunomodulation such as plasmapheresis, high dose corticosteroid and IVIG in severe leptospirosis. These treatment options are thought to have various effects on stopping excessive cytokines of the inflammatory process and reverses the disease-associated vasculitis. ${ }^{11-13}$ Meaudre et al. ${ }^{11}$ described a good clinical response to high dose methylprednisolone with IVIG in the treatment of severe leptospirosis. Thunga et al. ${ }^{12}$ and Trivedi et al. ${ }^{13}$ reported a favorable outcome following glucocorticoid pulse therapy in pulmonary leptospirosis. Jayakrishnan et al. ${ }^{14}$ successfully treated a 13 -year-old child with severe pulmonary involvement secondary to leptospirosis with high dose steroid and additionally other supportive therapies. In our case, however there was a gradual improvement in pulmonary findings, we did not observe favorable clinical response in the point of persitent high fever.

In conclusion, leptospirosis may cause TAMOF, persistent high fever and ARDS. Plasmapheresis 
and CVVHF with an endotoxin-cytokine cleaning filter should be considered in cases of severe leptospirosis which are complicated with ARDS, TAMOF, and persistent high fever.

\section{REFERENCES}

1. American Academy of Pediatrics: Leptospirosis. In: Pickering LK, Baker CJ, Kimberlin DW, Long SS, eds. Red Book:2012 Report of the Committee on Infectious Diseases. Elk Grove Village, IL: American Academy of Pediatrics; 2012: 469-471.

2. Forbes AE, Zochowski WJ, Dubrey SW, Sivaprakasam V. Leptospirosis and Weil's disease in the UK. QJM 2012; 105: 1151-1162.

3. Gulati S, Gulati A. Pulmonary manifestations of leptospirosis. Lung India 2012; 29: 347-353.

4. Ittyachen A, Lakshmanakumar VK, Eapen CK, Joseph MR. Methylprednisolone as adjuvant in treatment of acute respiratory distress syndrome owing to leptospirosis-a pilot study. Indian J Crit Care Med 2005; 9: 133-136.

5. Lingappa J, Kuffner T, Tappero J, et al. HLA-DQ6 and ingestion of contaminated water: possible geneenvironment interaction in an outbreak of Leptospirosis. Genes Immun 2004; 5: 197-202.

6. Haake DA, Levett PN. Leptospirosis in humans. Curr Top Microbiol Immunol 2015; 387: 65-97.

7. Sevketoglu E, Yildizdas D, Horoz OO, et al. Use of therapeutic plasma exchange in children with thrombocytopenia-associated multiple organ failure in the Turkish thrombocytopenia-associated multiple organ failure network. Pediatr Crit Care Med 2014; 15: 354-359.
8. Bourquin V, Ponte B, Hirschel B, Pugin J, Martin PY, Saudan P. Severe leptospirosis with multiple organ failure successfully treated by plasma exchange and high-volume hemofiltration. Case Rep Nephrol 2011; 2011: 817414

9. Honore PM, Jacobs R, Joannes-Boyau O, et al. Newly designed CRRT membranes for sepsis and SIRS--a pragmatic approach for bedside intensivists summarizing the more recent advances: a systematic structured review. ASAIO J 2013; 59: 99-106.

10. Esteban E, Ferrer R, Alsina L, Artigas A. Immunomodulation in sepsis: The role of endotoxin removal by polymyxin B-immobilized cartridge. Mediators Inflamm 2013; 2013: 507539.

11. Meaudre E, Asencio Y, Montcriol A, et al. Immunomodulation in severe leptospirosis with multiple organ failure: plasma exchange, intravenous immunoglobulin or corticosteroids? Ann Fr Anesth Reanim 2008; 27: 172-176.

12. Thunga G, John J, Sam KG, et al. Role of high-dose corticosteroid for the treatment of leptospirosis-induced pulmonary hemorrhage. J Clin Pharmacol 2012; 52: 114-116.

13. Trivedi SV, Chavda RK, Wadia PZ, et al. The role of glucocorticoid pulse therapy in pulmonary involvement in leptospirosis. J Assoc Physicians India 2001; 49: 901-903.

14. Jayakrishnan B, Ben Abid F, Balkhair A, et al. Severe Pulmonary Involvement in Leptospirosis: Alternate antibiotics and systemic steroids. Sultan Qaboos Univ Med J 2013; 13: 318-322. 